\title{
IL-6 mediated JAK/STAT3 signaling pathway in cancer patients with cachexia
}

\author{
Guney Eskiler $\mathrm{G}^{1}$, Bezdegumeli E², Ozman Z $\mathrm{Z}^{3}$, Deveci Ozkan $\mathrm{A}^{1}$, Bilir $\mathrm{C}^{4}$, Kucukakca BN², \\ Ince $\mathrm{MN}^{2}$, Men $\mathrm{AY}^{2}$, Aktas $\mathrm{O}^{2}$, Horoz $\mathrm{YE}^{2}$, Akpinar $\mathrm{D}^{2}$, Genc $\mathrm{I}^{2}$, Kaleli $\mathrm{S}^{1}$ \\ Department of Medical Biology, Faculty of Medicine, Sakarya University, Sakarya, Turkey. \\ gamzeguney@sakarya.edu.tr
}

\section{ABSTRACT}

OBJECTIVES: We investigated the changes in the IL-6 and STAT3 expression levels in cachectic and noncachectic patients with gastric, lung and breast cancer and evaluated the association between IL- 6 and STAT3 levels and cancer types in terms of cachexia condition.

BACKGROUND: Cancer-associated cachexia, observed in nearly $50-80 \%$ of cancer patients, has drawn attention in advanced patients. IL-6/JAK/STAT pathway plays an essential role in the progression of cancer cachexia through the regulation of the inflammatory response.

METHODS: This study consisted of 48 gastric, breast and lung cancer patients (18 cachectic and 30 noncachectic) and healthy individuals. Total RNA isolation and cDNA synthesis was performed after the collection of blood samples. IL-6 and STAT3 expression levels were analyzed by RT- PCR analysis.

RESULTS: Our findings demonstrated that IL-6 mRNA levels considerably increased $19.89 \pm 8.25,5.18 \pm 2.81$ and $15.33 \pm 9.54$-fold in gastric, lung and breast cancer patients with cachexia, respectively. Additionally, a $16.67 \pm 7.13,14.21 \pm 11.72$ and $8.85 \pm 3$.89-fold increase in the STAT3 expression level was detected in cachectic gastric, lung and breast cancer patients, respectively $(p<0.01)$.

CONCLUSION: STAT3 may be considered as a therapeutic target for cachectic patients with gastric, lung and breast cancer. Furthermore, IL-6 mediates STAT3 activation in cachectic gastric and breast cancer patients (Tab. 5, Fig. 2, Ref. 62). Text in PDF www.elis.sk.

KEY WORDS: cachexia, IL-6, STAT3, gastric cancer, lung cancer, breast cancer.

\section{Introduction}

Cachexia, which accounts for $20 \%$ cancer deaths, is a multifactorial syndrome and defined by weight loss $>5 \%$ or $>2 \%$ with a body mass index $(\mathrm{BMI})<20 \mathrm{~kg} / \mathrm{m}^{2}$ over 6 months and the loss of skeletal muscle $\left(<7.26 \mathrm{~kg} / \mathrm{m}^{2}\right.$ for males and $<5.45 \mathrm{~kg} / \mathrm{m}^{2}$ for females), adipose tissue and skeletal muscle mass. Therefore, cachexia is associated with a poor prognosis, toxicities, reduces overall survival and thus, cachexia has a negative impact on the quality of life in cancer patients. Furthermore, no beneficial effects are observed with parenteral nutrition and supplementation to treat cachectic cancer patients due to anorexia, anemia and systemic inflammation (1-6).

The interleukin 6 (IL-6) mediated Janus Kinase (JAK)/ Signal transducer and activator of transcription 3 (STAT3) pathway play an important role in cancer cachexia through induction of systemic

${ }^{1}$ Department of Medical Biology, Faculty of Medicine, Sakarya University, Sakarya, Turkey, ${ }^{2}$ Faculty of Medicine, Sakarya University, Sakarya, Turkey, ${ }^{3}$ Institute of Health Science, Department of Medical Biochemistry Sakarya University, Turkey and ${ }^{4}$ Department of Medical Oncology, Faculty of Medicine, Sakarya University, Sakarya, Turkey

Address for correspondence: G. Eskiler, PhD, Department of Medical Biology, Faculty of Medicine, Sakarya University, Korucuk, 54290, Sakarya, Turkey.

Phone: +90.02642954308 , Fax: +90.264 .2956629$ inflammatory response $(7,8)$. STAT3 is a transcription factor and aberrant activation of the phosphorylated STAT3 (pSTAT3) is involved in nearly $70 \%$ of human cancers due to promoting tumor growth through regulating multiple genes and/or pathways $(9,10)$. Interleukin 6 (IL-6) is an interleukin that mediates the immune response, the acute phase response and inflammation through its receptors (IL-6 receptor (IL-6R) and gp130). IL-6 is highly up-regulated during inflammation in response to tissue injury or stress and other pro-inflammatory cytokines (11-13). JAK/STAT is activated by the phosphorylation of IL- 6 tyrosine residues in the cytoplasmic domain of gp130. Thus, IL-6 plays a crucial role in the inflammation-mediated "cancers types", including prostate, breast, gastric, colon, lung and brain due to inducing different cytoplasmic tyrosine kinases and transcription factors and thus, overexpression of IL-6 is associated with poor prognosis in many cancers. Previous studies mentioned that IL-6 mediated STAT3 activation could be a therapeutic target in gastric, glioblastoma, breast, ovarian and lung cancer patients due to mediating muscle wasting (14-20). However, further studies are still needed to clarify the association between the changes in IL-6 and STAT- 3 levels and cancer patients with and without cachexia.

For this purpose, we for the first time investigated the expression level of IL-6 and STAT3 in cachectic and non-cachectic cancer patients levels with gastric, lung and breast cancer in comparison to the control groups, in order to identify the effect of IL-6 signaling 
819-826

Tab. 1. Primer sequences.

\begin{tabular}{lll}
\hline Gene Name & Direction & Primer sequence $\left(5^{\prime}-3^{\prime}\right)$ \\
\hline STAT3 & Forward & ATCACGCCTTCTACAGACTGC \\
STAT3 & Reverse & CATCCTGGAGATTCTCTACCACT \\
IL-6 & Forward & AACCTGAACCTTCCAAAGATGG \\
IL-6 & Reverse & TCTGGCTTGTTCCTCACTACT \\
\hline
\end{tabular}

Tab. 2. Clinical data of cancer patients with cachexia and without cachexia and healthy control subjects.

\begin{tabular}{|c|c|c|c|}
\hline & $\begin{array}{c}\text { Cachectic } \\
\text { cancer patients } \\
(n=18)\end{array}$ & $\begin{array}{l}\text { Non-cachectic } \\
\text { cancer patients } \\
(n=30)\end{array}$ & $\begin{array}{l}\text { Control } \\
(n=25)\end{array}$ \\
\hline Age (years) & $55.28 \pm 9.55$ & $61.80 \pm 10.02$ & $54.40 \pm 8.3$ \\
\hline Gender (M/F) & $9 / 9$ & $16 / 14$ & $13 / 12$ \\
\hline Tumor Types & $\begin{array}{c}\text { Gastric Cancer }(n=5) \\
\text { Invasive Ductal } \\
\text { Breast Cancer }(n=6) \\
\text { Lung Cancer }(n=7)\end{array}$ & $\begin{array}{c}\text { Gastric Cancer }(\mathrm{n}=10) \\
\text { Invasive Ductal } \\
\text { Breast Cancer }(\mathrm{n}=10) \\
\text { Lung Cancer }(\mathrm{n}=10)\end{array}$ & \\
\hline $\begin{array}{c}\text { Grade } \\
1 \\
2 \\
3\end{array}$ & $\begin{array}{l}6.3 \% \\
25.0 \% \\
68.8 \%\end{array}$ & $\begin{array}{l}22.7 \% \\
31.8 \% \\
45.5 \%\end{array}$ & \\
\hline $\begin{array}{c}\text { T Stage } \\
\text { T1 } \\
\text { T2 } \\
\text { T3 } \\
\text { T4 } \\
\end{array}$ & $\begin{array}{l}23.5 \% \\
11.8 \% \\
29.4 \% \\
35.3 \% \\
\end{array}$ & $\begin{array}{l}31.0 \% \\
20.7 \% \\
20.7 \% \\
27.6 \%\end{array}$ & \\
\hline $\begin{array}{c}\text { N stage } \\
\text { N0 } \\
\text { N1 } \\
\text { N2 } \\
\text { N3 } \\
\end{array}$ & $\begin{array}{l}16.7 \% \\
27.8 \% \\
33.3 \% \\
22.2 \% \\
\end{array}$ & $\begin{array}{l}14.3 \% \\
25.0 \% \\
35.7 \% \\
25.0 \%\end{array}$ & \\
\hline $\begin{array}{c}\text { M stage } \\
\text { M0 } \\
\text { M1 }\end{array}$ & $\begin{array}{l}33.3 \% \\
66.7 \%\end{array}$ & $\begin{array}{l}46.7 \% \\
53.3 \%\end{array}$ & \\
\hline Weight (kg) & $56.35 \pm 6.03$ & $76.10 \pm 12.32$ & $84.42 \pm 5.02$ \\
\hline $\mathrm{BMI}\left(\mathrm{kg} / \mathrm{m}^{2}\right)$ & $17.48 \pm 9.79$ & $28.85 \pm 7.31$ & $28.11 \pm 5.1$ \\
\hline $\begin{array}{l}\text { Total serum } \\
\text { protein }(\mathrm{g} / \mathrm{dL})\end{array}$ & $6.87 \pm 0.58$ & $6.66 \pm 1.54$ & $7.4 \pm 0.80$ \\
\hline Albumin (g/dL) & $3.7 \pm 9.52$ & $2.3 \pm 1.85$ & $4.2 \pm 0.30$ \\
\hline
\end{tabular}

on STAT3 activation in cancer cachexia. Furthermore, we explored the association between IL- 6 mediated the activation of STAT3 and gastric, lung and breast cancer patients with and without cachexia.

\section{Materials and methods}

\section{Patient population}

This study consisted of forty-eight patients $(n=48)$ with gastric, breast and lung cancer and the patients, were admitted to Sakarya University Faculty of Medicine Department of Oncology before any surgical or medical procedures. Patients, who had received prior treatment before admission were excluded. Eighteen of the patients $(n=18)$ presented with cachexia signs and symptoms during the study period and were diagnosed with cachexia by corresponding oncology physicians according to diagnostic criteria for cachexia. Thirty $(n=30)$ of the patients did not show cachexia symptomatology and maintained a higher BMI than cachectic cancer patients during the study period. The patients were categorized into six groups: cachectic patients with gastric $(n=5)$, lung $(n=7)$ and breast $(n=6)$ cancer and non- cachectic patients with gastric $(n=10)$, lung cancer $(n=10)$ and breast cancer $(n=$ 10) compared with healthy individuals as controls $(n=25)$. This study was approved by the Ethics Committee of Sakarya University (Application number: 16214662/050.01.04/23) and written consent was obtained from all the patients included in this study.

\section{Total RNA isolation and cDNA synthesis}

Blood samples from patients were collected and stored at $-80^{\circ} \mathrm{C}$ for RNA isolation. Total RNA was isolated by Purelink RNA Mini Kit (Invitrogen, Cat. 12183018A) according to the manufacturer's instructions. The concentration of total RNA was analyzed by Qubit RNAAssay Kit and Qubit 4 Fluorometer (Invitrogen/Molecular Probes). Then, 100 ng of total RNA was reverse transcribed with High Capacity cDNA Reverse Transcription Kit (Applied Biosystems).

\section{Real-time PCR (RT-PCR) analysis}

In order to analyze the changes in IL-6 and STAT3 expression levels, RT- PCR was performed in 96-well optical reaction plates with a StepOnePlus Real-Time PCR Systems (v. 2.0, Applied Biosystems) by SYBR Green mix. ACTB was used for the reference gene. Primer sequences of IL-6 and STAT3 were shown in Table 1.

\section{Statistical analysis}

Statistical analysis was performed by the SPSS software package, version 21.0 (SPSS Inc. USA). All data were expressed as the mean \pm standard deviation (SD) and One-Way ANOVA analysis with Post-Tukey test was performed for multiple comparison. Univariate ANOVA analysis was used to determine the interaction IL-6 and STAT3 levels with cancer types in terms of cancer cachexia. The percent difference was calculated by $\Delta \%$ formula (21). The fold change of the IL-6 and STAT3 levels was statistically analyzed by software (https://www.qiagen.com/tr/shop/ genes-and-pathways/data-analysis-center overview-page/otherreal-time-pcr-probes-or-primers-data-analysis-center/). Statistical significance was set at $\mathrm{p}<0.05$.

\section{Results}

\section{Patients characteristic}

From April 2017 to April 2018, 48 cancer patients (18 cachectic and 30 non-cachectic) and 25 healthy controls were included in this study and clinical characteristic of cachectic and non-cachectic cancer patients included to the study were presented in Tables 2 and 3. In terms of age, the cachectic and non-cachectic cancer patients in each cancer type (gastric, lung and breast cancer patients) and controls were similar. The average age of gastric, lung and breast cachectic cancer patients was $61.80 \pm 10.04,59.00 \pm 3.46$ and 45.50 \pm 6.22 (mean $\pm \mathrm{SD}$ ), respectively compared with non-cachectic patients with gastric, lung and breast cancer $(65.90 \pm 9.62,65.40 \pm$ 5.56 and $54.10 \pm 10.4$, respectively). BMI was significantly lower in cachectic cancer patients than in non-cachectic patients and the control. However, cachectic gastric and lung cancer patients indicated a significantly less BMI values than breast cancer patients. 
Tab. 3. Characteristics of patients with gastric, lung and breast cancer with cachexia and without cachexia.

\begin{tabular}{|c|c|c|c|c|c|c|}
\hline & \multicolumn{3}{|c|}{ Cachectic } & \multicolumn{3}{|c|}{ Non-Cachectic } \\
\hline & $\begin{array}{l}\text { Gastric cancer } \\
\text { patients }(n=5)\end{array}$ & $\begin{array}{l}\text { Lung cancer } \\
\text { patients }(n=7)\end{array}$ & $\begin{array}{l}\text { Breast cancer } \\
\text { patients }(n=6)\end{array}$ & $\begin{array}{l}\text { Gastric cancer } \\
\text { patients }(n=10)\end{array}$ & $\begin{array}{c}\text { Lung cancer } \\
\text { patients }(n=10)\end{array}$ & $\begin{array}{l}\text { Breast cancer } \\
\text { patients }(n=10)\end{array}$ \\
\hline Age (years) & $61.80 \pm 10.04$ & $59.00 \pm 3.46$ & $45.50 \pm 6.22$ & $65.90 \pm 9.62$ & $65.40 \pm 5.56$ & $54.10 \pm 10.4$ \\
\hline Gender (M/F) & $5 / 0$ & $4 / 3$ & $0 / 6$ & $6 / 4$ & $10 / 0$ & $0 / 10$ \\
\hline \multicolumn{7}{|l|}{ Grade } \\
\hline 1 & $0.0 \%$ & $0.0 \%$ & $16.7 \%$ & $14.3 \%$ & $0.0 \%$ & $40.0 \%$ \\
\hline 2 & $20.0 \%$ & $0.0 \%$ & $50.0 \%$ & $28.6 \%$ & $20.0 \%$ & $40.0 \%$ \\
\hline 3 & $80.0 \%$ & $100.0 \%$ & $33.3 \%$ & $57.1 \%$ & $80.0 \%$ & $20.0 \%$ \\
\hline \multicolumn{7}{|l|}{ T Stage } \\
\hline $\mathrm{T} 1$ & $0.0 \%$ & $0.0 \%$ & $66.7 \%$ & $22.2 \%$ & $0.0 \%$ & $70.0 \%$ \\
\hline $\mathrm{T} 2$ & $0.0 \%$ & $16.7 \%$ & $16.7 \%$ & $11.1 \%$ & $30.0 \%$ & $20.0 \%$ \\
\hline $\mathrm{T} 3$ & $80.0 \%$ & $16.7 \%$ & $0.0 \%$ & $33.3 \%$ & $20.0 \%$ & $10.0 \%$ \\
\hline $\mathrm{T} 4$ & $20.0 \%$ & $66.7 \%$ & $16.7 \%$ & $33.3 \%$ & $50.0 \%$ & $0.0 \%$ \\
\hline \multicolumn{7}{|l|}{$\overline{\mathrm{N}}$ stage } \\
\hline No & $20.0 \%$ & $14.3 \%$ & $16.7 \%$ & $12.5 \%$ & $0.0 \%$ & $30.0 \%$ \\
\hline N1 & $20.0 \%$ & $0.0 \%$ & $66.7 \%$ & $12.5 \%$ & $10.0 \%$ & $50.0 \%$ \\
\hline $\mathrm{N} 2$ & $0.0 \%$ & $71.4 \%$ & $16.7 \%$ & $12.5 \%$ & $40.0 \%$ & $20.0 \%$ \\
\hline N3 & $60.0 \%$ & $14.3 \%$ & $0.0 \%$ & $62.5 \%$ & $50.0 \%$ & \\
\hline \multicolumn{7}{|l|}{$\bar{M}$ stage } \\
\hline M0 & $0.0 \%$ & $14.35 \%$ & $83.3 \%$ & $60.0 \%$ & $20.0 \%$ & $60.0 \%$ \\
\hline M1 & $100 \%$ & $85.7 \%$ & $16.7 \%$ & $40.0 \%$ & $80.0 \%$ & $40.0 \%$ \\
\hline Weight (kg) & $54.50 \pm 4.04$ & $55.29 \pm 6.73$ & $58.83 \pm 7.44$ & $69.20 \pm 9.26$ & $76.5 \pm 4.10$ & $83.00 \pm 11.71$ \\
\hline BMI $\left(\mathrm{kg} / \mathrm{m}^{2}\right)$ & $18.90 \pm 1.36$ & $19.84 \pm 5.64$ & $24.48 \pm 3.82$ & $23.80 \pm 3.41$ & $25.50 \pm 1.82$ & $33.90 \pm 6.70$ \\
\hline $\begin{array}{l}\text { Total serum } \\
\text { Protein }(\mathrm{g} / \mathrm{dL}) \\
\end{array}$ & $6.60 \pm 0.1$ & $6.64 \pm 0.59$ & $7.43 \pm 0.35$ & $5.6 \pm 2.29$ & $7.08 \pm 2.37$ & $7.23 \pm 0.51$ \\
\hline Albumin (g/dL) & $3.28 \pm 0.53$ & $3.85 \pm 0.06$ & $4.2 \pm 0.2$ & $2.06 \pm 1.84$ & $2.37 \pm 1.70$ & $22.47 \pm 2.16$ \\
\hline
\end{tabular}

IL-6 and STAT3 expression levels in cancer patients with or without cachexia

The expression levels of IL- 6 and STAT3 were analyzed in gastric $(n=5)$, lung $(n=7)$ and breast cancer $(n=6)$ with cachexia compared with non-cachectic gastric $(\mathrm{n}=10)$, lung $(\mathrm{n}=$ $10)$ and breast cancer patients $(n=10)$ and healthy group $(n=25)$ as indicated in Figure 1. In gastric, lung and breast cancer patients with cachexia, IL-6 mRNA levels remarkably increased $19.89 \pm$ $8.25,5.18 \pm 2.81$ and $15.33 \pm 9.54$-fold, respectively $(\mathrm{p}<0.01)$ compared to the control group $(0.67 \pm 0.50)$. Additionally, a 4.48 $\pm 2.10(\mathrm{p}=0.004)$ and $4.62 \pm 3.53$-fold $(\mathrm{p}=0.026)$ increase in IL-6 expression level was observed in gastric and breast cancer patients without cachexia. However, the expression of IL-6 was higher in non-cachectic lung cancer patients $(8.03 \pm 4.38)$ than in cachectic patients $(5.18 \pm 2.81 ; \mathrm{p}<0.01)$. Furthermore, the STAT3 expression level was significantly higher in gastric (16.67 \pm 7.13$)$, lung $(14.21 \pm 11.72)$ and breast cancer $(8.85 \pm 3.89)$ patients with cachexia $(\mathrm{p}<0.01)$ compared to the control group $(0.78 \pm 0.40)$. In cancer patients without cachexia, STAT3 expression level increased by $1.72 \pm 0.72(\mathrm{p}=0.587), 5.83 \pm 4.99(\mathrm{p}=0.037)$ and $2.03 \pm 0.88$-fold $(\mathrm{p}=0.102)$ in gastric, lung and breast cancer patients, respectively.

The association between IL-6 and STAT3 expression levels and cancer types

We compared the association between IL- 6 and STAT3 expression levels and patients with cachexia and without cachexia in terms of cancer type (gastric, lung and breast). In Figure 2, the changes in the expression level of IL- 6 was significant between gastric and lung cancer patients $(p=0.009)$ with cachexia. Additionally, there was a significant difference between gastric and lung cancer patients $(\mathrm{p}=0.012)$ or lung and breast cancer patients $(p=0.021)$ without cachexia according to STAT3 expression level. However, there was no significant difference in STAT3 as well as IL-6 levels among cachectic cancer patients.

We performed univariate ANOVA analysis to statistically compare cachectic and non-cachectic cancer patients in terms of cancer type and IL-6 and STAT3 expression levels. In Table 4, all the measured values of IL-6 expression level were statistically different in cachectic and non-cachectic gastric, lung and breast cancer patients $(p<0.05)$. Besides, the interaction between cancer type and cachexia status was statistically significant $(\mathrm{F}=13.127$; $\mathrm{p}=0.001$ ). Thus, IL-6 mRNA level was higher in cachectic lung and breast cancer patients than in non-cachectic cancer patients. When the ratio of percentage differences in the IL- 6 level was evaluated between cachectic and non-cachectic patients, there was $79.07 \%$, and $69.86 \%$ increase in gastric and breast cancer patients, respectively. However, the expression of IL-6 decreased by $-55.01 \%$ in lung cancer patients with cachexia. When the ratio of percentage differences in the IL- 6 level among the types of cancer was examined, there was $-40.09 \%-11.22 \%$ and 20.60 $\%$ differences between the lung and gastric cancer patients, the breast and gastric cancer patients and the breast and lung cancer patients, respectively.

Furthermore, all the measured values of STAT3 mRNA level were statistically different in gastric, lung and breast cancer pa- 
819-826

IL-6

A

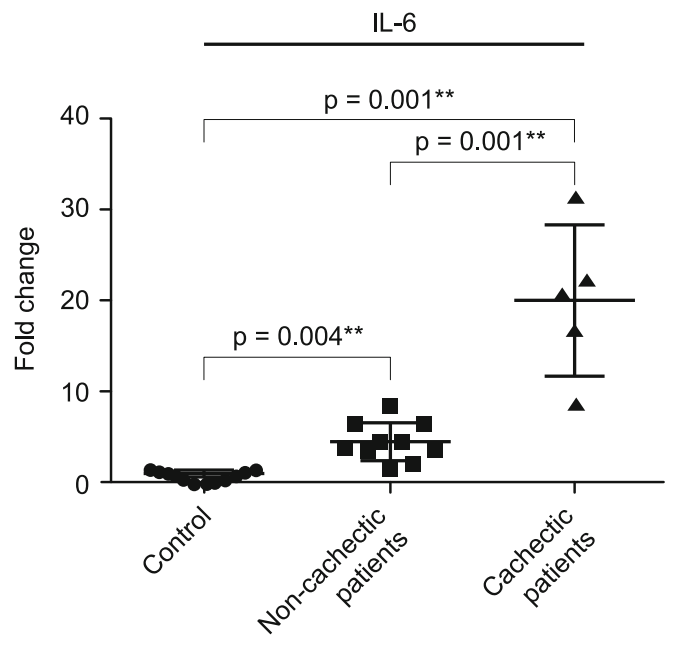

B

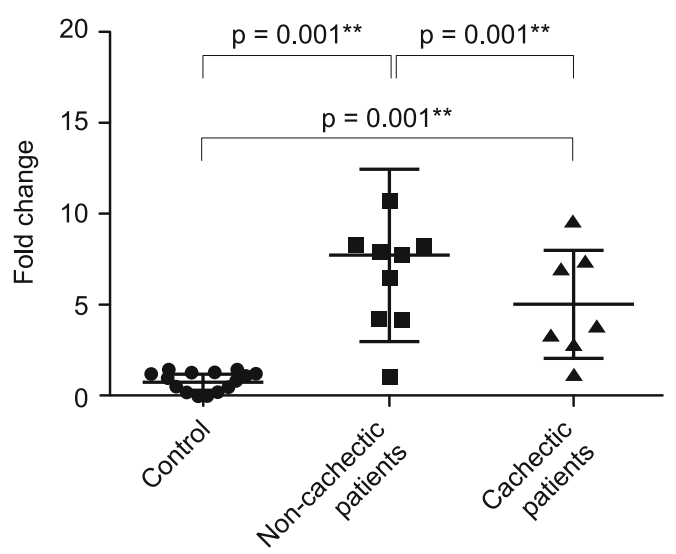

(C)

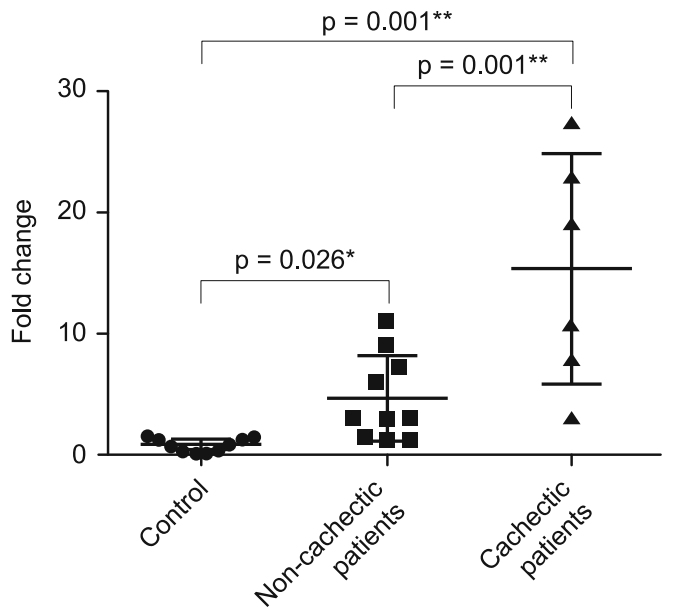

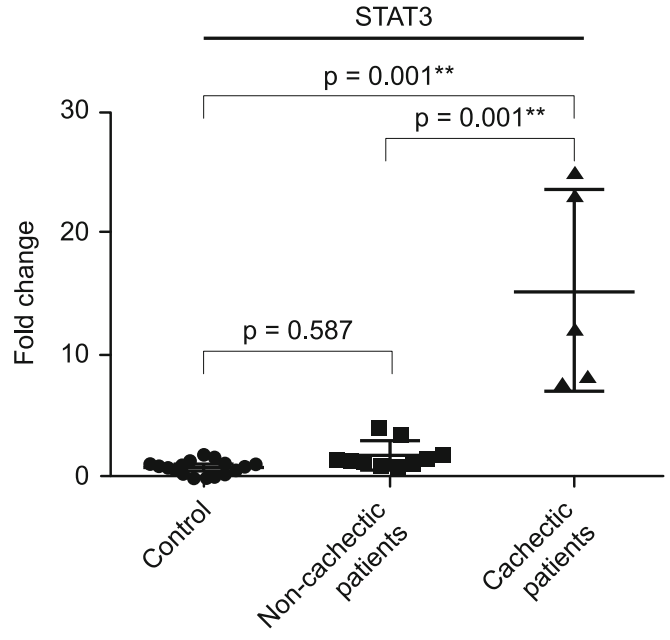
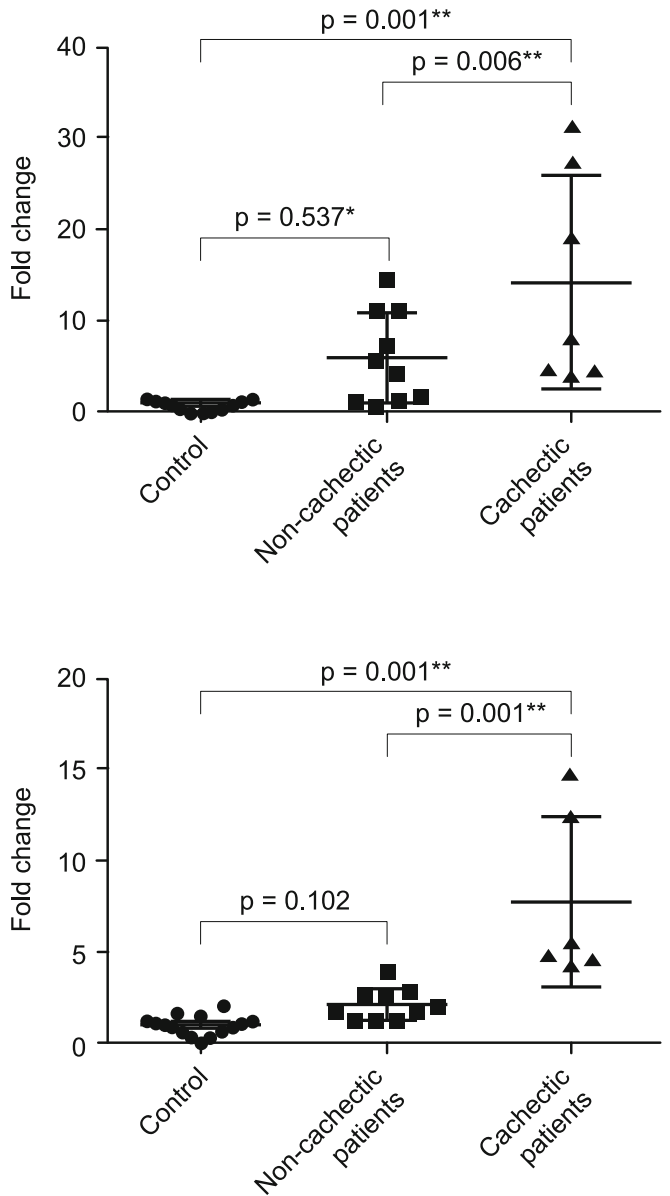

Fig. 1. The mRNA level of IL-6 and STAT3 in cachectic and non-cachectic cancer patients compared to the healthy subjects. (A) Gastric, (B) Lung and (C) Breast cancer patients $\left({ }^{*} p<0.05,{ }^{* *} p<0.01\right)$.

tients in Table $5(\mathrm{p}<0.05)$. Additionally, the expression of STAT3 was statistically different according to the cachectic and non-cachectic status $(\mathrm{p}<0.01)$. The interaction between the cancer type and cachexia status was statistically significant $(\mathrm{F}=3.204 ; \mathrm{p}=$ 0.047). Therefore, STAT3 expression level was higher in cancer patients with cachexia than without cachexia. When the ratio of percentage differences in the STAT3 level between cachectic and non-cachectic patients were investigated, there was $89.68 \%, 58.98$ $\%$ and $77.06 \%$ increase in the STAT3 levels of gastric, lung and breast cancer patients with cachexia, respectively compared with 

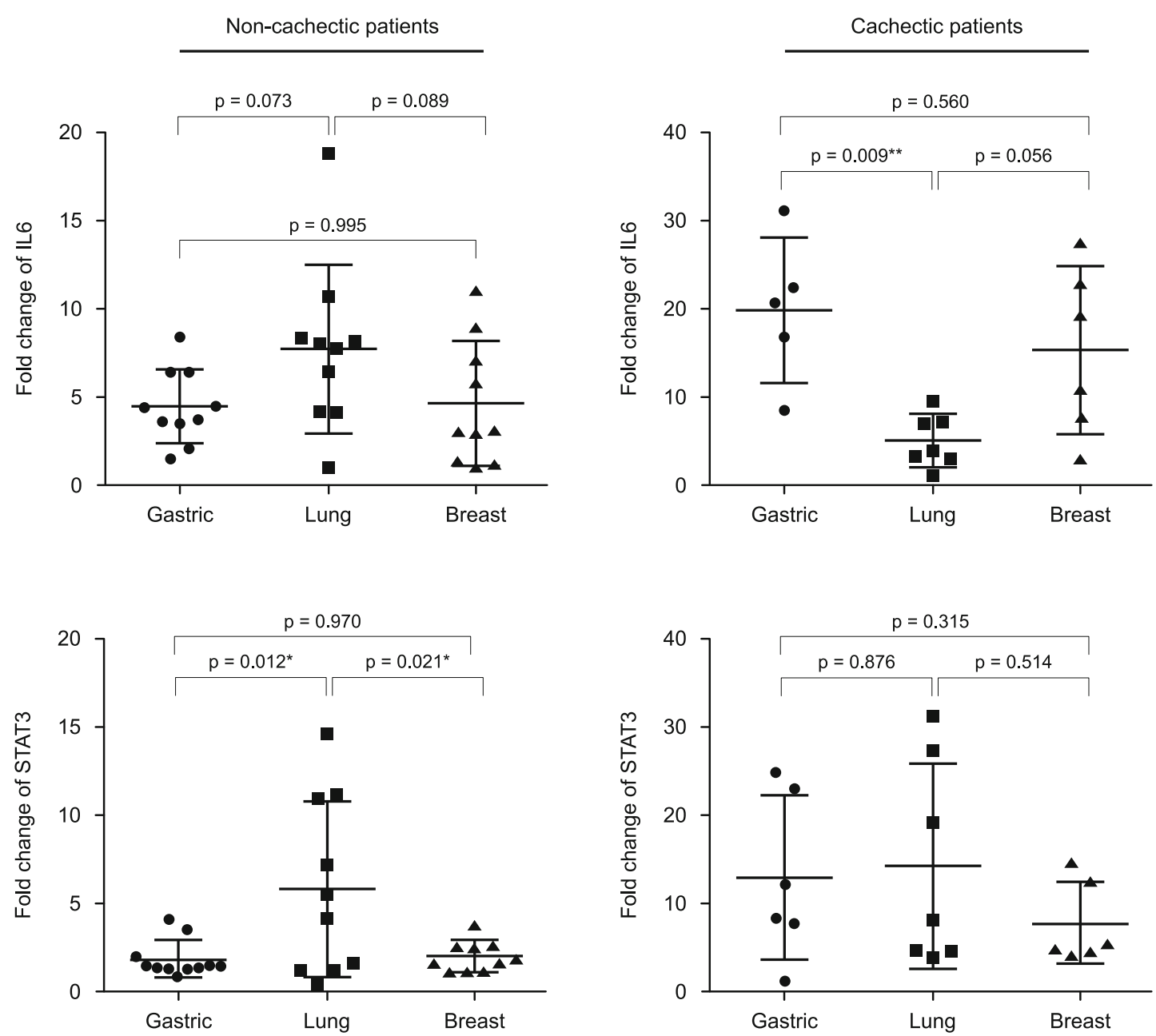

Fig. 2. Comparison of IL-6 and STAT3 level in gastric, lung and breast cancer patients according to cachectic and non-cachectic condition (*p $<0.05, * *$ p $<0.01)$.

non-cachectic groups. When the ratio of percentage differences in the STAT3 level among the types of cancer were examined, there was $27.69 \%,-46.19 \%$ and $-102.18 \%$ differences between the lung and gastric cancer patients, the breast and gastric cancer patients and the breast and lung cancer patients, respectively.

\section{Discussion}

Cachexia is a multifactorial syndrome observed in advancedstage cancer patients, which has a considerable impact on patient prognosis and is a major cause of mortality (1-6). As the molecular mechanisms underlying cachexia have not been fully elucidated yet, new molecular biomarkers of cancer cachexia are urgently explored. In the literature, single nucleotide polymorphism in different genes and cytokines, differentially expressed alternatively spliced genes (DASGs), some cytokine (IL-6, and TNF- $\alpha$ ) serum levels and epigenetic mechanisms have been associated with cachexia in patients with gastric, head and neck, pancreatic and lung cancer (22-32). Additionally, recent studies have indicated that high systemic IL-6 levels are linked to worse prognosis in different cancer patients (gastric, non-small lung, pancreas etc.) (33-35). However, no prior studies have examined the association IL-6mediated STAT3 activation between cancer patients with cancer cachexia, to our knowledge. In the present study, we for the first time investigated the association between the expression levels of IL-6 and STAT3 in patients with cachectic and non-cachectic gastric, lung and breast cancer. We found that IL-6 mRNA level was significantly higher in cachectic gastric and breast cancer patients than non-cachectic patients $(\mathrm{p}<0.01)$. Additionally, STAT-3 level was remarkably higher in all types of cancer patients with cachexia at any TNM stage than non-cachectic patients $(\mathrm{p}<0.01)$. However, cachectic lung cancer patients indicated lower IL-6 mRNA levels than patients without cachexia. Furthermore, there was a significant interaction between IL-6 and STAT-3 mRNA level and cancer types in terms of cancer cachexia.

According to an epidemiological analysis of cachexia in patients with advanced cancer $(n=140)$, the prevalence of cachexia in gastric cancer patients was determined as $76.5 \%$ (36). Inflammation is one of the most important cause in the development of gastric cancer. In the inflammatory process, different cytokines 
Tab. 4. Comparison of IL-6 expression level in cachectic and non-cachectic cancer patients.

\begin{tabular}{|c|c|c|c|c|c|c|c|}
\hline \multirow[t]{2}{*}{ Grup\&Cancer Types } & \multirow[t]{2}{*}{$\mathrm{N}$} & $\begin{array}{l}\text { Cachectic patients } \\
\qquad(\mathrm{n}=18)\end{array}$ & $\begin{array}{l}\text { Non- Cachectic patients } \\
\qquad(\mathrm{n}=30)\end{array}$ & \multirow[t]{2}{*}{$\% \Delta$} & $\begin{array}{c}\text { Total } \\
(n=48)\end{array}$ & \multirow[t]{2}{*}{$\mathrm{F}$} & \multirow[t]{2}{*}{$\mathrm{p}$} \\
\hline & & $\overline{\mathrm{X}} \pm \mathrm{SD}$ & $\overline{\mathrm{X}} \pm \mathrm{SD}$ & & $\overline{\mathrm{X}} \pm \mathrm{SD}$ & & \\
\hline Gastric $\left(X_{1}\right)$ & 15 & $19.89 \pm 8.25$ & $4.48 \pm 2.10$ & 79.07 & $9.61 \pm 8.88^{\mathrm{a}}$ & \multirow{3}{*}{4.518} & \multirow{3}{*}{$0.017 *$} \\
\hline Lung $\left(\mathrm{X}_{2}\right)$ & 17 & $5.18 \pm 2.81$ & $8.03 \pm 4.38$ & -55.01 & $6.86 \pm 3.98^{\mathrm{b}}$ & & \\
\hline Breast $\left(\mathrm{X}_{3}\right)$ & 16 & $15.33 \pm 9.54$ & $4.62 \pm 3.53$ & 69.86 & $8.64 \pm 8.15^{\mathrm{ab}}$ & & \\
\hline Total & 48 & $12.65 \pm 9.30$ & $5.71 \pm 3.74$ & & $8.31 \pm 7.17$ & \multirow{2}{*}{\multicolumn{2}{|c|}{$\begin{array}{l}\text { Grup X Cancer Types Interaction } \\
\qquad \mathrm{F}=13.127 ; \mathrm{p}=0.001 * *\end{array}$}} \\
\hline \multicolumn{6}{|c|}{$\mathrm{F}=25.534 ; \mathrm{p}=0.001 * *$} & & \\
\hline$\% \Delta\left(X_{2}-X_{1}\right)$ & & & & & -40.09 & & \\
\hline$\% \Delta\left(X_{3}-X_{1}\right)$ & & & & & -11.22 & & \\
\hline$\% \Delta\left(\mathrm{X}_{3}-\mathrm{X}_{2}\right)$ & & & & & 20.60 & & \\
\hline
\end{tabular}

Tab. 5. Comparison of STAT3 expression level in cachectic and non-cachectic cancer patients.

\begin{tabular}{|c|c|c|c|c|c|c|c|}
\hline \multirow[t]{2}{*}{ Grup \& Cancer Types } & \multirow[t]{2}{*}{$\mathrm{N}$} & $\begin{array}{l}\text { Cachectic patients } \\
\qquad(\mathrm{n}=18)\end{array}$ & $\begin{array}{l}\text { Non- Cachectic patients } \\
\qquad(\mathrm{n}=30)\end{array}$ & \multirow[t]{2}{*}{$\% \Delta$} & $\begin{array}{c}\text { Total } \\
(\mathrm{n}=48)\end{array}$ & \multirow[t]{2}{*}{$\mathrm{F}$} & \multirow[t]{2}{*}{$\mathrm{p}$} \\
\hline & & $\overline{\mathrm{X}} \pm \mathrm{SD}$ & $\overline{\mathrm{X}} \pm \mathrm{SD}$ & & $\overline{\mathrm{X}} \pm \mathrm{SD}$ & & \\
\hline Gastric $\left(X_{1}\right)$ & 15 & $16.67 \pm 7.13$ & $1.72 \pm 0.72$ & 89.68 & $6.71 \pm 8.25^{\mathrm{ab}}$ & \multirow{3}{*}{4.473} & \multirow{3}{*}{$0.015 *$} \\
\hline Lung $\left(\mathrm{X}_{2}\right)$ & 17 & $14.21 \pm 11.72$ & $5.83 \pm 4.99$ & 58.98 & $9.28 \pm 9.14^{\mathrm{a}}$ & & \\
\hline Breast $\left(\mathrm{X}_{3}\right)$ & 16 & $8.85 \pm 3.89$ & $2.03 \pm 0.88$ & 77.06 & $4.59 \pm 4.14^{\mathrm{b}}$ & & \\
\hline Total & 48 & $13.11 \pm 8.69$ & $3.19 \pm 3.43$ & & $4.81 \pm 6.82$ & \multirow{2}{*}{\multicolumn{2}{|c|}{$\begin{array}{l}\text { Grup X Cancer Types Interaction } \\
\qquad \mathrm{F}=3.204 ; \mathrm{p}=0.047^{*}\end{array}$}} \\
\hline \multicolumn{5}{|c|}{$\mathrm{F}=55.210 ; \mathrm{p}=0.001 * *$} & & & \\
\hline$\% \Delta\left(X_{2}-X_{1}\right)$ & & & & & 27.69 & & \\
\hline$\% \Delta\left(X_{3}-X_{1}\right)$ & & & & & -46.19 & & \\
\hline$\% \Delta\left(\mathrm{X}_{3}-\mathrm{X}_{2}\right)$ & & & & & -102.18 & & \\
\hline
\end{tabular}

such as TNF alpha, IL-1, IL-6, IL-10 induce the activation of intracellular signaling pathways including PI3K/AKT and JAK/STAT (37-40). Additionally, Helicobacter pylori infection is linked to an increased risk of developing gastric cancer due to alteration the expression level of IL-6 $(41,42)$. Furthermore, some studies have also showed that gastric cancer patients with liver metastases have higher levels of IL- 6 compared to the healthy controls and high serum IL-6 level is associated with tumor invasion, tumor size and lymph node metastasis and IL-6 mediated STAT3 activation plays a crucial role in increasing tumor size and proliferation of gastric cancer (43-48). Our results demonstrated that IL-6 and STAT3 expression level were considerably higher in cachectic gastric cancer patients levels compared to the non-cachectic and healthy control group $(\mathrm{p}<0.01)$. Therefore, our findings suggest that high IL-6 and STAT3 mRNA level is associated with the development of cachexia and poor prognosis in gastric cancer patients.

In the literature, $45.6 \%$ of patients receiving chemotherapy with advanced lung cancer present cancer cachexia signs and symptoms. Therefore, cachexia is commonly prevalent in particularly lung and gastrointestinal cancer patients (49). In the study of patients with different stages of lung cancer, IL-6 level was upregulated compared with healthy subjects (33). Additionally, Miller et al (2017) state that IL-6 induces hyperactivation of STAT3 transcription factor via IL-6 cytokine family signaling receptor, gp130, and IL- 6 regulated STAT3 activation results in cachexia during Kras-driven lung carcinogenesis, in vivo (18). In the present study, we found that the expression level of IL-6 was higher in cachectic and non-cachectic lung cancer patients than in the healthy controls $(p<0.05)$. Interestingly, the mRNA level of IL-6 was lower in lung cancer patients with cachexia than that in patients without cachexia. According to these findings, the downregulation of STAT3 level in cachectic lung cancer patients could be expected. It is known that IL-6 induces STAT3 activation via gp130 receptor dimerization, which recruits STAT3. STAT3 is then phosphorylated, initiating the activation of multiple-genes associated with inflammation $(14,15)$. However, STAT3 expression is also regulated by different cytokines such as: TNF $\alpha$, IL-11, IL-22, IFN $\alpha$ and IFN $\beta$ and signaling pathways $(\mathrm{NF}-\kappa \beta)(50-52)$. Our findings indicated that the expression level of STAT3 was significantly higher in cachectic lung cancer patient than non-cachectic patients $(\mathrm{p}<0.01)$ and thus STAT3 could be a therapeutic marker in lung cancer patients. However, the changes in STAT3 expression levels could possibly be regulated by different cytokines and signaling pathways. Thus, the underlying molecular signaling pathways of STAT3 activation and associated cytokines should be further investigated.

Although cachexia is generally observed in pancreatic, gastric, colorectal, lung, and head and neck cancer, recent studies have provided a compelling evidence that there is a relationship between advance metastatic breast cancer and cachexia due to a decrease in muscle mass and excessive weight loss (53-55). Recent studies have also demonstrated that a high level of IL- 6 is associated with cachexia, angiogenesis, atrophy, increased catabolism of muscle protein 
and resistance to treatment in advance breast cancer $(2,35,56)$. Furthermore, breast cancer patients with high levels of IL-6 compared to the heathy control groups indicate cachexia symptoms and are characterized by weight loss $(33,57,58)$. Additionally, the activation of JAK/STAT, PI3K, and MAPK pathways linked to cancer metastasis, tumor cell proliferation, differentiation, apoptosis, angiogenesis and invasion have been identified in patients with breast cancer (59-62). In our study, the expression levels of IL-6 and STAT-3 were significantly higher in cachectic and non-cachectic breast cancer patients than that of the control group, and especially these mRNA levels were up-regulated in breast cancer with cachexia. Thus, IL6- mediated STAT3 signaling could be a promising biomarker in cachectic breast cancer patients as well as gastric cancer patients.

\section{Conclusion}

Our results suggest that STAT3 could be used as a prognostic biomarker in gastric, lung and breast cancer patients with cachexia and IL-6 mediated STAT3 activation in cachectic gastric and breast cancer patients. Additionally, the association between IL-6 and STAT3 levels and cancer types in terms of cancer cachexia was statistically significant.

However, further studies are required to explore IL6-mediated STAT3 activation in larger cohorts of gastric, lung and breast patients with cachexia or other cancer types.

\section{References}

1. Fearon K, Strasser F, Anker SD, Bosaeus I, Bruera E, Fainsinger RL et al. Definition and classification of cancer cachexia: an international consensus. Lancet Oncol 2011; 12 (5): 489-495.

2. Aoyagi T, Terracina KP, Raza A, Matsubara H, Takabe K. Cancer cachexia, mechanism and treatment. World J Gastrointest Oncol 2015; 7 (4): $17-29$.

3. Donohoe CL, Ryan AM, Reynolds JV. Cancer cachexia: mechanisms and clinical implications. Gastroenterol Res Pract 2011; 2011: 601434.

4. Porporato PE. Understanding cachexia as a cancer metabolism syndrome. Oncogenesis 2016; 5 (2): e200.

5. Baracos VE. Cancer-associated cachexia and underlying biological mechanisms. Annu Rev Nutr 2006; 26: 435-461.

6. Baracos VE, Martin L, Korc M, Guttridge DC, Fearon KCH. Cancerassociated cachexia. Nat Rev Dis Primers 2018; 4: 17105.

7. Yu H, Pardoll D, Jove R. STATs in cancer inflammation and immunity: a leading role for STAT3. Nat Rev Cancer 2009; 9 (11): 798-809.

8. Costa-Pereira AP, Bonito NA, Seckl MJ. Dysregulation of janus kinases and signal transducers and activators of transcription in cancer. Am J Cancer Res 2011; 1 (6): 806.

9. Carpenter RL, Lo HW. STAT3 Target Genes Relevant to Human Cancers. Cancers 2014; 6 (2): 897-925.

10. Fagard R, Metelev V, Souissi I, Baran-Marszak F. STAT3 inhibitors for cancer therapy: Have all roads been explored? Jak-Stat 2013; 2 (1): e22882.

11. Strassmann G, Fong M, Kenney JS, Jacob CO. Evidence for the involvement of interleukin 6 in experimental cancer cachexia. J Clin Invest 1992; 89 (5):1681-1684.
12. Hunter CA, Jones SA. IL-6 as a keystone cytokine in health and disease. Nat Immunol 2015; 16 (5): 448.

13. Mihara M, Hashizume M, Yoshida H, Suzuki M, Shiina M. IL-6/ IL-6 receptor system and its role in physiological and pathological conditions. Clinical science 2012; 122 (4): 143-159.

14. Johnson DE, O'Keefe RA, Grandis JR. Targeting the IL-6/JAK/ STAT3 signalling axis in cancer. Nat Rev Clin Oncol 2018; 15 (4): 234.

15. Zimmers TA, Fishel ML, Bonetto A. STAT3 in the systemic inflammation of cancer cachexia. Semin Cell Dev Biol 2016; 54: 28-41.

16. Heo TH, Wahler J, Suh N. Potential therapeutic implications of IL-6/IL-6R/gp130-targeting agents in breast cancer. Oncotarget 2016; 7 (13): $15460-15473$.

17. West AJ, Tsui V, Stylli SS, Nguyen HPT, Morokoff AP, Kaye AH et al. The role of interleukin-6-STAT3 signalling in glioblastoma. Oncol Lett 2018; 16 (4): 4095-4104.

18. Miller A, McLeod L, Alhayyani S, Szczepny A, Watkins DN, Chen W et al. Blockade of the IL-6 trans-signalling/STAT3 axis suppresses cachexia in Kras-induced lung adenocarcinoma. Oncogene 2017; 36 (21): 3059-3066.

19. Browning L, Patel MR, Horvath EB, Tawara K, Jorcyk CL. IL-6 and ovarian cancer: inflammatory cytokines in promotion of metastasis. Cancer Manag Res 2018; 10: 6685-6693.

20. Wang Z, Si X, Xu A, Meng X, Gao S, Qi Y et al. Activation of STAT3 in human gastric cancer cells via interleukin (IL)-6-type cytokine signaling correlates with clinical implications. PLoS One 2013; 8 (10): e75788.

21. Isik O, Dogan I. Effects of bilateral or unilateral lower body resistance exercises on markers of skeletal muscle damage. Biomed J 2018; 41 (6): 364-368.

22. Powrózek T, Mlak R, Brzozowska A, Mazurek M, Golębiowski P, Malecka-Massalska T. miRNA-130a Significantly Improves Accuracy of SGA Nutritional Assessment Tool in Prediction of Malnutrition and Cachexia in Radiotherapy-Treated Head and Neck Cancer Patients. Cancers (Basel) 2018; 10 (9): 294.

23. Song B, Zhang D, Wang S, Zheng H, Wang X. Association of interleukin-8 with cachexia from patients with low-third gastric cancer. Comp Funct Genomics 2009; 2009: 212345

24. Narasimhan A, Greiner R, Bathe OF, Baracos V, Damaraju S. Differentially expressed alternatively spliced genes in skeletal muscle from cancer patients with cachexia. J Cachexia Sarcopenia Muscle 2018; 9 (1): 60-70.

25. Carr RM, Enriquez-Hesles E, Olson RL, Jatoi A, Doles J, Fernandez-Zapico ME. Epigenetics of cancer-associated muscle catabolism. Epigenomics 2017.

26. Pessina P, Conti V, Pacelli F, Rosa F, Doglietto GB, Brunelli S et al. Skeletal muscle of gastric cancer patients expresses genes involved in muscle regeneration. Oncol Rep 201024 (3): 741-745.

27. Johns N, Stretch C, Tan BH, Solheim TS, Sørhaug S, Stephens NA et al. New genetic signatures associated with cancer cachexia as defined by low skeletal muscle index and weight loss. J Cachexia Sarcopenia Muscle 2017; 8 (1): 122-130.

28. Fujiwara Y, Kobayashi T, Chayahara N, Imamura Y, Toyoda M, Kiyota $\mathbf{N}$ et al. Metabolomics evaluation of serum markers for cachexia and their intra-day variation in patients with advanced pancreatic cancer. PLoS One 2014; 9 (11): e113259. 
29. Skorokhod A, Bachmann J, Giese NA, Martignoni ME, KrakowskiRoosen H. Real-imaging cDNA-AFLP transcript profiling of pancreatic cancer patients: Egr-1 as a potential key regulator of muscle cachexia. BMC Cancer 2012; 12 (1): 265.

30. Powrózek T, Mlak R, Brzozowska A, Mazurek M, Gołębiowski P, Malecka-Massalska T. Relationship between TNF- $\alpha-1031 \mathrm{~T} / \mathrm{C}$ gene polymorphism, plasma level of TNF- $\alpha$, and risk of cachexia in head and neck cancer patients. J Cancer Res Clin Oncol 2018; 144 (8): 1423-1434.

31. Johns N, Tan BH, MacMillan M, Solheim TS, Ross JA, Baracos VE et al. Genetic basis of interindividual susceptibility to cancer cachexia: selection of potential candidate gene polymorphisms for association studies. J Genet 2014; 93 (3): 893-916.

32. Solheim TS, Fayers PM, Fladvad T, Tan B, Skorpen F, Fearon K et al. Is there a genetic cause for cancer cachexia? - a clinical validation study in 1797 patients. Br J Cancer 2011; 105 (8): 1244-51.

33. Silva EM, Mariano VS, Pastrez PRA, Pinto MC, Castro AG, Syrjanen KJ et al. High systemic IL-6 is associated with worse prognosis in patients with non-small cell lung cancer. PLoS One 2017; 12 (7): e0181125.

34. Miura T, Mitsunaga S, Ikeda M, Shimizu S, Ohno I, Takahashi H et al. Characterization of patients with advanced pancreatic cancer and high serum interleukin-6 levels. Pancreas 2015; 44 (5): 756-763.

35. Vainer N, Dehlendorff C, Johansen JS. Systematic literature review of IL-6 as a biomarker or treatment target in patients with gastric, bile duct, pancreatic and colorectal cancer. Oncotarget 2018; 9 (51): 29820-29841.

36. Sun L, Quan XQ, Yu S. An Epidemiological Survey of Cachexia in Advanced Cancer Patients and Analysis on Its Diagnostic and Treatment Status. Nutr Cancer 2015; 67 (7): 1056-1062.

37. UIIman TA, Itzkowitz SH. Intestinal inflammation and cancer. Gastroenterology 2011; 140 (6): 1807-1816.

38. Mantovani A, Allavena P, Sica A, Balkwill F. Cancer-related inflammation. Nature 2008; 454 (7203): 436-444.

39. Yu H, Pardoll D, Jove R. STATs in cancer inflammation and immunity: a leading role for STAT3. Nat Rev Cancer 2009; 9 (11): 798-809.

40. Yoshimura A. Signal transduction of inflammatory cytokines and tumor development. Cancer Sci 2006; 97 (6): 439-447.

41. Kang JM, Kim N, Lee DH, Park JH, Lee MK, Kim JS et al. The effects of genetic polymorphisms of IL-6, IL-8, and IL-10 on Helicobacter pylori-induced gastroduodenal diseases in Korea. J Clin Gastroenterol 2009; 43 (5): 420-428.

42. Matysiak-Budnik T, Mégraud F. Helicobacter pylori infection and gastric cancer. Eur J Cancer 2006; 42 (6): 708-716.

43. Wang Z, Si X, Xu A, Meng X, Gao S, Qi Y et al. Activation of STAT3 in Human Gastric Cancer Cells via Interleukin (IL)-6-Type Cytokine Signaling Correlates with Clinical Implications. PloS one 2013; 8 (10): e75788.

44. Zhou F, Cheng L, Qiu LX, Wang MY, Li J, Sun MH et al. Associations of potentially functional variants in IL-6, JAKs and STAT3 with gastric cancer risk in an eastern Chinese population. Oncotarget 2016; 7 (19): 28112-28123.

45. Zhao G, Zhu G, Huang Y, Zheng W, Hua J, Yang S, Ye J. IL-6 mediates the signal pathway of JAK-STAT3-VEGF-C promoting growth, invasion and lymphangiogenesis in gastric cancer. Oncology reports; 2016; 35 (3): 1787-1795.

46. Kim DK, Oh SY, Kwon HC, Lee S, Kwon KA, Kim BG et al. Clinical significances of preoperative serum interleukin- 6 and C-reactive protein level in operable gastric cancer. BMC Cancer 2009; 9 (1): 155.
47. Liao WC, Lin JT, Wu CY, Huang SP, Lin MT, Wu ASH et al. Serum interleukin-6 level but not genotype predicts survival after resection in stages II and III gastric carcinoma. Clin Cancer Res 2008; 14 (2): 428-434.

48. Bartsch R, Woehrer S, Raderer M, Hejna M. Serum interleukin-6 levels in patients with gastric MALT lymphoma compared to gastric and pancreatic cancer. Anticancer Res 2006; 26 (4B): 3187-3190.

49. Zhu R, Liu Z, Jiao R, Zhang C, Yu Q, Han S, Duan Z. Updates on the pathogenesis of advanced lung cancer-induced cachexia. Thorac Cancer 2019; 10 (1): 8-16.

50. Turner MD, Nedjai B, Hurst T, Pennington DJ. Cytokines and chemokines: At the crossroads of cell signalling and inflammatory disease. Biochim Biophys Acta 2014; 1843 (11): 2563-2582.

51. Ma JF, Sanchez BJ, Hall DT, Tremblay AK, Di Marco S, Gallouzi IE. STAT3 promotes IFN $\gamma / \mathrm{TNF} \alpha$-induced muscle wasting in an NF- $\mathrm{kB}$-dependent and IL-6-independent manner. EMBO Mol Med 2017; 9 (5): 622-637.

52. Bonetto A, Aydogdu T, Jin X, Zhang Z, Zhan R, Puzis L et al. JAK/ STAT3 pathway inhibition blocks skeletal muscle wasting downstream of IL-6 and in experimental cancer cachexia. Am J Physiol Endocrinol Metab 2012; 303 (3): 410-421.

53. Consul N, Guo X, Coker C, Lopez-Pintado S, Hibshoosh H, Zhao B et al. Monitoring Metastasis and Cachexia in a Patient with Breast Cancer: A Case Study. Clin Med Insights Oncol 2016; 10: 83-94.

54. Bohlen J, McLaughlin SL, Hazard-Jenkins H, Infante AM, Montgomery C, Davis M et al. Dysregulation of metabolic-associated pathways in muscle of breast cancer patients: preclinical evaluation of interleukin-15 targeting fatigue. J Cachexia Sarcopenia Muscle 2018; 9 (4): 701-714.

55. Ibrahimi M, Jamalzei B, Akbari ME, Ibrahimi R, Alaei M, Moossavi M et al. Association between interleukin 4 (IL-4) VNTR, gene polymorphism, and breast cancer susceptibility in Iranian population: experimental and web base analysis. Bratisl Med J 2018; 119 (10): 651-654.

56. White JP. IL-6, cancer and cachexia: metabolic dysfunction creates the perfect storm. Transl Cancer Res 2017; 6 (Suppl 2): 280-285.

57. Nariţa D, Seclaman E, Ursoniu S, Ilina R, Cireap N, Anghel A. Expression of CCL18 and interleukin-6 in the plasma of breast cancer patients as compared with benign tumor patients and healthy controls. Rom J Morphol Embryol 2011; 52 (4): 1261-1267.

58. Liu Q, Yu S, Li A, Xu H, Han X, Wu K. Targeting interlukin-6 to relieve immunosuppression in tumor microenvironment. Tumour Biol 2017; 39 (6).

59. Butti R, Das S, Gunasekaran VP, Yadav AS, Kumar D, Kundu GC. Receptor tyrosine kinases (RTKs) in breast cancer: signaling, therapeutic implications and challenges. Mol Cancer 2018; 17 (1): 34.

60. Velloso FJ, Bianco AF, Farias JO, Torres NE, Ferruzo PY, Anschau $\mathbf{V}$ et al. The crossroads of breast cancer progression: insights into the modulation of major signaling pathways. Onco Targets Ther 2017; 10: 5491-5524.

61. Kruger DT, Beelen KJ, Opdam M, Sanders J, van der Noort V, Boven $\mathbf{E}$ et al. Hierarchical clustering of activated proteins in the PI3K and MAPK pathways in ER-positive, HER2-negative breast cancer with potential therapeutic consequences. Br J Cancer 2018; 119 (7): 832-839.

62. Kubikova E, Badidova J, Klein M, Beder I Jr, Benus R, Polak S et al. Sentinel lymph node - historical background and current views on its significance in complex management of breast cancer patients. Bratisl Med J 2019; 120 (6): 410-416.

Received May 27, 2019. Accepted July 2, 2019. 